\title{
Predictive System of COVID -19 Using Response Based Analytical Model
}

\author{
Dr. Pallavi Mirajkar'1, Dr. Rupali Dahake² \\ ${ }^{1}$ Department of Computer Science, M. D. College, Parel, Mumbai, , Maharashtra, India \\ ${ }^{2}$ Researcher, Pune, Maharashtra, India
}

\section{ABSTRACT}

\section{Article Info}

Volume 7, Issue 2

Page Number : 05-10

Publication Issue :

March-April-2021

\section{Article History}

Accepted : 01 March 2021

Published : 06 March 2021
The novel COVID sickness 2019 (COVID-19) pandemic caused by the SARSCoV-2 keeps on representing a serious and vital threat to worldwide health. This pandemic keeps on testing clinical frameworks around the world in numerous viewpoints, remembering sharp increments in requests for clinic beds and basic deficiencies in clinical equipments, while numerous medical services laborers have themselves been infected. We have proposed analytical model that predicts a positive SARS-CoV-2 infection by considering both common and severe symptoms in patients. The proposed model will work on response data of all individuals if they are suffering from various symptoms of the COVID-19. Consequently, proposed model can be utilized for successful screening and prioritization of testing for the infection in everyone.

Keywords: Covid-19, Prediction, Analytical Model, Symptoms, Response Based System

\section{INTRODUCTION}

Corona viruses are a family of viruses which will cause illnesses like the cold, severe acute respiratory syndrome (SARS) and Middle East respiratory syndrome (MERS). In 2019, a replacement corona virus was identified because the explanation for a disease outbreak that originated in China. The virus is now referred to as the severe acute respiratory syndrome corona virus 2 (SARS-CoV-2). The disease it causes is named corona virus disease 2019 (COVID19). In March 2020, the planet Health Organization (WHO) declared the COVID-19 outbreak an epidemic.

The COVID-19 pandemic has triggered an urgent got to contribute to the fight against an immense threat to the human population. Computer Vision, as a subfield of AI, has obtained recent success in solving various complex problems in health care and has the potential to contribute to the fight of controlling COVID-19. In response to the present call, computer vision researchers are putting their knowledge domain at work to plan effective ways to counter COVID-19 challenge and serve the worldwide community. COVID 19, disease is caused by severe acute respiratory syndrome (SARS-CoV-2) [1]. The fight against COVID 19 has motivated researchers worldwide to explore, understand, and devise new diagnostic and treatment techniques to culminate this threat to our generation. Computer science vision community is fighting with this menace by proposing new approaches, improving efficiency, and speed of the existing efforts. Computer science vision is an interdisciplinary field that deals with how computers can develop a high-level understanding by

Copyright: () the author(s), publisher and licensee Technoscience Academy. This is an open-access article distributed under the terms of the Creative Commons Attribution Non-Commercial License, which permits unrestricted non-commercial use, distribution, and reproduction in any medium, provided the original work is properly cited 
interpreting information present in digital images. Computer vision techniques have shown enormous scope in various applications areas, especially in healthcare and medical research. This success has enabled computer vision scientists to require the challenge as soldiers within the fight against COVID19 by contributing to disease diagnosis, prognosis, prevention, control, treatment and management.[3]

\section{RELATED WORK}

Aishwarya Kumar* et.al investigated that every probable choice for struggle the corona virus epidemic, While technology advances have entered into our day by day lives with numerous victories, they have likewise widow to helping people in the very intense wrestle versus COVID19. Author stated that the present models acquired extraordinary accuracy in recognizing COVID-19 symptoms with different sorts of viral infection utilizing radiology pictures but lacks transparency and interpretability. It are often conclude that there's a good scope of potential utilizations of recent technologies covering clinical and cultural difficulties made by the coronavirus pandemic; but not many of them are immediately develop enough to point out operational effect.[2]

Ulhaq* et. al presented an in depth survey of computer vision efforts and methods to combat the COVID-19 pandemic challenge and also gave a quick review of the representative work so far. Author has categorized methods into three categories supported their role in disease control: computerized tomography (CT) scans, X-ray Imagery, and Prevention and Control.[3]

Muhammad, L.J., Islam, M.M., Usman, S.S. et al. have investigated that the data mining algorithm which incorporates DT, SVM,NB,LR, RF, and K-NN were applied directly on the dataset using python programming language. The model predicted a minimum and maximum number of days for COVID19 patients to get over the virus. The model also predicted the age bracket of patients who are at high risk to not get over the COVID-19 pandemic, those that are likely to recover and people who might be likely to recover quickly from COVID-19 pandemic. They stated that from the performance evaluation results of the models, the model developed with DT data processing algorithm is efficiently capable of predicting the likelihood of recovery of infected patients from COVID-19 pandemic with the general accuracy [6]. WWMNSB Wijekoon and Dr. TMKK Jinasena has investigated that the prediction of COVID-19 presence during a person was administered by using four sorts of classification algorithms. Google co-labs was used because the platform to implement the python codebase and perform the research. The accuracy was calculated using the confusion matrix and consistent with the calculations logistics, the regression classification algorithm has shown the very best testing accuracy (90.97\%) [9].

L. J. Muhammad and et.al. has stated that data mining models were developed for the prediction of COVID19 infected patients' recovery using epidemiological dataset of COVID-19 patients of South Korea. DT, SVM, NB, LR, RF, and K-NN algorithms were applied directly on the dataset using python programming language. The model developed with DT was found to be the foremost efficient with the very best percentage of accuracy [10].

Krishna and Pravin Kumar V has stated that data mining algorithms were evolved and prognosis the student's problems during COVID-19 from the survey data set. LR, RF,

DT, K-NN, NB, and SVM algorithms were tested on the student's dataset using weka software. Author 
identified that the model evolved with DT was examined to be the foremost methodical with the many percentage accuracy of $95.85 \%$, with Comparatively RF-88.06, LR-87.52, SVM 92.85, KNN-89.60, and NB-90.49. The models are often utilized in Education sector to seek out the answer of student's problems during COVID-19 [11].

Sunidhi Shrivastava and Pankaj Gugnani concluded that predicting the coronavirus patient rate, KNN Clustering and ARIMA based AI method applied. Author found that experiment results of all the prediction by applying all methodologies for predicting COVID-19 Patient. The results of study shown the prediction of the coronavirus patient within the near future. In proposed work author has utilized Machine learning and AI technology ARIMA and $\mathrm{KNN}$ based Clustering used for the clustering [14]. Menni, C. et al has stated that a total of $2,618,862$ participants reported their potential symptoms of COVID-19 on a smartphone-based app. Author has figure out about how many people has gone through corono virus test. Author has proposed model combining symptoms to predict probable infection was applied to the data from all app users who reported symptoms $(805,753)$ and predicted that 140,312 (17.42\%) participants are likely to have COVID-19 [18].

\section{PROPOSED WORK}

Corona viruses are a family of viruses which will cause illnesses like the cold, severe acute respiratory syndrome (SARS) and Middle East respiratory syndrome (MERS). In 2019, a replacement corona virus was identified because the explanation for a disease outbreak that originated in China.

COVID-19 may be a respiratory condition caused by a corona virus. Some people are infected but don't notice any symptoms. Most of the people will have mild symptoms and shown better recovery with their own. But about 1 in 6 will have severe problems, like trouble breathing. The chances of more serious symptoms are higher if you're older or have another health condition like diabetes or heart condition. Researchers in China found that the foremost common symptoms among people that were hospitalized with COVID-19 include:

$$
\begin{aligned}
& \text { - } \text { Fever } \\
& \text { - Fatigue } \\
& \text { - A dry cough } \\
& \text { - Loss of appetite } \\
& \text { - } \text { Body aches } \\
& \text { - Shortness of breath } \\
& \text { - Mucus or phlegm }
\end{aligned}
$$

Symptoms usually begin 2 to 14 days after you come into contact with the virus [5]. Other symptoms may include:

$$
\begin{aligned}
& \text { - Sore throat } \\
& \text { - } \text { Headache } \\
& \text { - } \quad \text { Loss of smell or taste } \\
& \text { - Congestion or runny nose } \\
& \text { - Nausea or vomiting } \\
& \text { - Diarrhea }
\end{aligned}
$$

The scale of symptoms severity may have different, varying from maximum to minimum severe, Here, We are scaling one, two and three levels. The risk factor scale may be numerical or descriptive. Here, we cover a range from the minimum to the maximum as of occurrence and varies from one, two and three.

The impact of risk factors is the results from the combination of risk factors and symptoms, as follows:

$$
\text { Formulae: } W\left(R_{i}\right)=R_{i} S_{i} \quad \rightarrow(1)
$$

Where, $R_{i}$ is occurrence of risk factors and $S_{i}$ is the Symptoms observed in COVID prediction system. 
Dr. Pallavi Mirajkar et al Int. J. Sci. Res. Comput. Sci. Eng. Inf. Technol, March-April-2021, 7 (2) : 05-10

\begin{tabular}{|c|ccc|}
\hline \multirow{2}{*}{$\begin{array}{c}\text { Risk } \\
\text { Factors }\end{array}$} & \multicolumn{3}{|c|}{ Symptoms } \\
\cline { 2 - 4 } & Slight & Serious & $\begin{array}{c}\text { Very } \\
\text { serious }\end{array}$ \\
\hline Low & 1 & 2 & 3 \\
Moderated & 2 & 4 & 6 \\
High & 3 & 6 & 9 \\
\hline
\end{tabular}

Table No.1: Severity of Risk Factors

Table No. 1 shows the risk impact matrix, with a three-level qualitative and numerical scale for both variables (Risk factors exposed and symptoms). For each combination of different possibilities for each variable, the risk level is shown.

\begin{tabular}{|cc|}
\hline $\begin{array}{c}\text { Risk Factor Scale } \\
\text { Description }\end{array}$ & $\begin{array}{c}\text { Symptoms Scale } \\
\text { Description }\end{array}$ \\
\hline $\begin{array}{c}\text { Risk exposed, but its } \\
\text { probability is negligible. }\end{array}$ & Slight \\
\hline $\begin{array}{c}\text { Risk factor is exposed but } \\
\text { very less frequently }\end{array}$ & Serious \\
\hline Risk factor is exposed but & $(2)$ \\
with more frequently & Very serious \\
\hline
\end{tabular}

Table No. 2 Description of Risk Factors and Symptoms

\begin{tabular}{|rl|}
\hline \multicolumn{2}{|c|}{ The score are classified into the following grades: } \\
\hline $1-2:$ & Low risk \\
\hline $3-4:$ & Medium risk \\
\hline $5-6:$ & High risk \\
\hline $7-9:$ & Extreme risk \\
\hline
\end{tabular}

Table No. 3 Ranges of the Score

\section{Working Model}

Step 1: Give Input to model $\mathrm{C}=\{1,2,3 \ldots \ldots \mathrm{i})$.
Where $\mathrm{i}=$ Total Number of common

Symptoms. $S=\{1,2,3 \ldots . j)$.

Where $j=$ total Number Severe

Symptoms. $R=\{1,2,3 \mathrm{k}\}$

Where $\mathrm{k}=$ Total number risk factors considered.

Step 2: Enter the type of symptom common or severe symptoms.

Step 3: Enter the severity of symptoms and occurrence of risk factor exposed.

Step 4: calculate formulae (1) as above

Step 5: Design Matrix for each $C$ and $S$ with risk impact level $\mathrm{W}(\mathrm{R})$.

Step 6: Calculate the Risk score for Common symptoms C

Common Risk Score $=\sum_{K=1}^{p}\left(\sum_{i=1}^{m} \mathrm{C}_{\mathrm{i}} * \mathrm{~W}\left(\mathrm{R}_{\mathrm{k})}\right)\right.$

Step 7: Calculate the Risk score for severe symptoms $\mathrm{S}$

Severe Risk Score $=\sum_{K=1}^{p}\left(\sum_{j=1}^{n} \mathrm{~S}_{\mathrm{j}} * \mathrm{~W}\left(\mathrm{R}_{\mathrm{k}}\right)\right)$

Step 8: Display the resultant value in prediction system.

Step 9: Highlight the result and provide the solution set as per medical expertise.

\section{CONCLUSION}

Coronavirus pandemic is spreading its wings across the globe at a shockingly faster rate and has just brought about huge number of death across nations. A general exhaustive examination on investigation of COVID-19, its prediction, effects, and control measures are introduced in this investigation. This analytical model analyzed two important attributes for predicting coronavirus are symptoms and risk factors. The model first checks symptoms, if symptoms exist, then the risk factors and its severity are examined. From this model, we conclude that analytical model can be employed to predict outbreak 
spreading trend are at high risk of developing Covid complications. We hope that prediction of Covid-19 using response based analytical models will be more useful for adjusting better mediation arrangements earlier, it will also help to alleviate the alarming impact of this pandemic.

\section{REFERENCES}

[1]. C. I. Paules, H. D. Marston, and A. S. Fauci, "Coronavirus Infections-More Than Just the Common Cold," JAMA, vol. 323, no. 8, pp. 707708, 2020.

[2]. Aishwarya Kumar, Puneet Kumar Gupta* , Ankita Srivastava A review of modern technologies for tackling COVID-19 pandemic , / Diabetes \& Metabolic Syndrome: Clinical Research \& Reviews 14 (May 2020) (569-573).

[3]. Ulhaq, Anwaar \& Khan, Asim \& Gomes, Douglas \& Paul, Manoranjan. (2020). Computer Vision for COVID-19 Control: A Survey. 10.31224/osf.io/yt9sx.

[4]. Tao Liu, Wenjia Liang, Haojie Zhong, Jianfeng He, Zihui Chen, Guanhao He, Tie Song, Shaowei Chen, Ping Wang, Jialing Li, Yunhua Lan, Mingji Cheng, Jinxu Huang, Jiwei Niu, Liang Xia, Jianpeng Xiao, Jianxiong Hu, Lifeng Lin, Qiong Huang, Zuhua Rong, Aiping Deng, Weilin Zeng, Jiansen Li, Xing Li, Xiaohua Tan, Min Kang, Lingchuan Guo, Zhihua Zhu, Dexin Gong, Guimin Chen, Moran Dong \& Wenjun $\mathrm{Ma}$ (2020) Risk factors associated with COVID19 infection: a retrospective cohort study based on contacts tracing, EmergingMicrobes\& Infections, 9:1, 1546- 1553, DOI: 10.1080/22221751.2020.178779 9 | Received 18 May 2020, Accepted 22 Jun 2020, Accepted author version posted online: 01 Jul 2020, Published online:07 Jul 2020.

[5]. World Health Organization (2020). WHO coronavirus disease (COVID19) dashboard. https://covid19.who.int/. Accessed on 17 July 2020.

[6]. Muhammad, L.J., Islam, M.M., Usman, S.S. et al. Predictive Data Mining Models for Novel Coronavirus (COVID-19) Infected https://doi.org/10.1007/s42979-020-00216- w.

[7]. Albahri AS, Hamid RA, Alwan JK, Al-Qays ZT, Zaidan AA, Zaidan BB, Albahri AOS, AlAmoodi AH, Khlaf JM, Almahdi EM, Thabet E, Hadi SM, Mohammed KI, Alsalem MA, AlObaidi JR, Madhloom HT. Role of biological Data Mining and Machine Learning Techniques in Detecting and Diagnosing the Novel Coronavirus (COVID-19): A Systematic Review. J Med Syst. 2020 May 25;44(7):122. doi: $\quad 10.1007 / s 10916-020-01582-x P M I D$ : 32451808; PMCID: PMC7247866.

[8]. https://www.webmd.com/lung/covid-19symptoms\# 1

[9]. WWMNSBWijekoon\#1,DrTMKK Jinasena2 "Predict the presence of COVID19usingclassificationtechniques"- Conference Paper · December 2020

[10]. L. J. Muhammad, Md. Milon Islam, Sani Sharif Usman,Safial Islam Ayon "Predictive Data Mining Models for Novel Coronavirus (COVID-19) Infected Patients' Recovery" Received: 31 May 2020 / Accepted: 3 June 2020 / Published online: 21 June 2020 (C) Springer Nature Singapore Pte Ltd 2020 SN ComputerScience(2020)1:206 https://doi.org/10.1007/s42979-020-00216- w

[11]. Krishna , Pravin Kumar V “ Prediction and Analysis of Data Mining Models for Students Underlying Issues during Novel Coronavirus (COVID-19)" International Journal of Engineering Research \& Technology (IJERT) ISSN: 2278-0181 Published by, www.ijert.org NCAIT - 2020 Conference Proceedings. 
[12]. Yazeed Zoabi , Shira Deri-Rozov and Noam Shomron "Machine learning-based prediction of COVID-19 diagnosis.

[13]. based on symptoms" npj Digital Medicine (2021) 4:3 ; https://doi.org/10.1038/s41746020-00372-6.

[14]. Sunidhi Shrivastava, Pankaj Gugnani "Data Mining Prediction Models for Novel Coronavirus (COVID-19) using Machine Learning" Electronic copy available at: https://ssrn.com/abstract=3759263

[15]. Huang C, Wang Y, Li X, Ren L, Zhao J, Hu Y, et al. Clinical features of patients infected with 2019 novel coronavirus in Wuhan, China. Lancet 2020;395:497-506.

[16]. Zhu N, Zhang D, Wang W, Li X, Yang B, Song J, et al. A novel coronavirus from patients with pneumonia in China, 2019. N Engl J Med 2020;382(8):727-33.

[17]. The Novel Coronavirus Israel Ministry of Health https://govextra.gov.il/ministry-of health/corona/corona-virus-en/ (2020).

[18]. Menni, C. et al. Real-time tracking of selfreported symptoms to predict potential COVID-19.NatMed26,1037-1040(2020).

\section{Biography:}

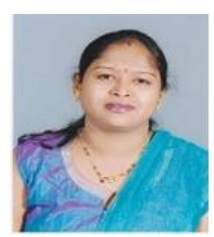

Dr. Pallavi Mirajkar, Head, Dept. of Comp. Sci, M. D. College, Parel, Mumbai-12

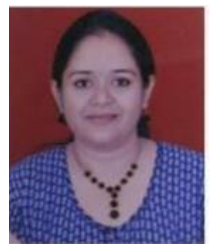

Dr. Rupali Dahake passed M.Sc. (Computer Science) from North Maharashtra University, Jalgaon. Currently Ph.D. from Pacific University, Udaipur.

\section{Cite this article as :}

Dr. Pallavi Mirajkar, Dr. Rupali Dahake,, "Predictive System of COVID -19 Using Response Based Analytical Model", International Journal of Scientific Research in Computer Science, Engineering and Information Technology (IJSRCSEIT), ISSN : 24563307, Volume 7 Issue 2, pp. 05-10, March-April 2021. Available at

doi : https://doi.org/10.32628/CSEIT21725

Journal URL : https://ijsrcseit.com/CSEIT21725 